\title{
ELECTROSTATIC BENEFICIATION OF COAL
}

Identification Number: DE-FG22-93PC93203

Grant Period: October 1, 1993 to September 31, 1996

QUARTERLY TECHNICAL PROGRESS REPORT

April 1, 1996 to June 30, 1996

$$
\text { DOE/PC/93203--T6 }
$$

DEC 231969

Submitted by

M. K. Mazumder (PI), D. Lindquist (Co-PI), and K. B. Tennal (Co-PI)

University of Arkansas at Little Rock

2801 S. University

Little Rock, AR 72204

Submitted to

Document Control Center

U.S. Department of Energy

Pittsburgh Energy Technology Center

PO BOX 10940, MS 921-118

Pittsburgh, PA 15236-0940

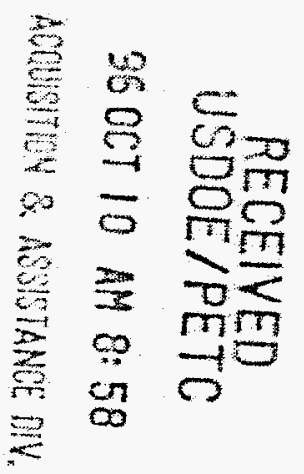

July 1996

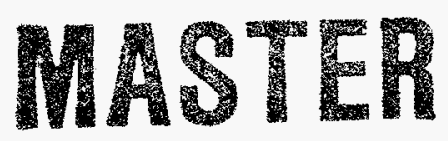

DISTRIBUTION OF THIS DOCUMENT IS UNLANTED

$$
\text { in }
$$




\section{DISCLAIMER}

This report was prepared as an account of work sponsored by an agency of the United States Government. Neither the United States Government nor any agency thereof, nor any of their employees, make any warranty, express or implied, or assumes any legal liability or responsibility for the accuracy, completeness, or usefulness of any information, apparatus, product, or process disclosed, or represents that its use would not infringe privately owned rights. Reference herein to any specific commercial product, process, or service by trade name, trademark, manufacturer, or otherwise does not necessarily constitute or imply its endorsement, recommendation, or favoring by the United States Government or any agency thereof. The views and opinions of authors expressed herein do not necessarily state or reflect those of the United States Government or any agency thereof. 


\section{DISCLAMMER}

Portions of this document may be illegible in electronic image products. Images are produced from the best available original document. 
U.S./DOE Patent Clearance is not required prior to publication of this document.

ELECTROSTATIC BENEFICIATION OF COAL

DOE PROJECT ID\#: DE-FG22-93PC93203

Quarterly Technical Progress Report

April 1, 1996 to June 30, 1996

\section{INTRODUCTION}

This report outlines the progress made during the eleventh quarter of the project, from April 1, 1996 to June 30, 1996. We have requested and received a six month no-cost extension on the project. This will allow one Ph.D. student to complete experimental studies related to his research. The extension is also related to a significant learning curve in the implementation of petrographic analysis in the project and to the need for additional instrumental development, specifically, extending the size range of the E-SPART Analyzer and Image Analyzer.

\section{WORK PERFORMED IN THE ELEVENTH QUARTER}

\section{Modification to the Electrostatic Separator}

Results have indicated a need to modify the electrostatic separator. First the total percent material recovered from the plates and the filter has been variable including some runs where more coal was recovered than was input. This indicates that powder is deposited in the charger or in the expansion cone with subsequent release of these on later runs. Also a high fraction of particles end up on the filter paper at the bottom of the separator. This applies to both large and small particles. Changes in the separator were thus made.

The goals of the modifications were 1) to increase the fraction of particles recovered for analysis after each run, 2) to reduce losses in the charging system, 3) to increase the fraction of particles collected on the plates. Several steps were involved in arriving at a suitable configuration. First the length of the separator electrodes was increased from 18 to 36 inches. The expansion cone was removed. The original intent of the expansion cone was to slow the particle flow rate prior to entering the separator section and, thus, to reduce deposition and coagulation due to turbulence. It became apparent that high concentrations of charged particles 
in the expansion cone caused high space charge. The resulting mutual repulsion forces caused deposition of particles inside the cone. Without the expansion cone the gas velocity leaving the charger is around $10 \mathrm{~m} / \mathrm{s}$ while the velocity of the surrounding sheath air was typically less than one meter per second. To reduce the negative effects of the subsequent turbulence the spacing between the separator plates was increased at the top from $10 \mathrm{~cm}$ to $25 \mathrm{~cm}$. The plates were angled such that the spacing between them decreased linearly to $10 \mathrm{~cm}$ at the bottom just above the filter. The electric field is thus higher at the bottom of the plates than the top. This may be an advantage since particles remaining in the flow at the lower part of the separator should have lower electrical mobility and thus require higher field for separation.

The modifications resulted in the recovery of a larger fraction of the coal fed into the charger and in a higher fraction recovered on the separator plates relative to the filter. For presieved coal at -140 mesh the fraction recovered from the plates was $98 \%$ while the fraction recovered from the filter was about $1 \%$.

\section{Review of DOE Specifications for Minimum Beneficiation and Calculations of grinding requirements based on washability}

A 1989 DOE-PETC report (DE90007159) specifies as the goals of beneficiation 80\% energy recovery, $70 \%$ pyritic sulfur rejection and ash content of less than $3 \%$. The particles to be separated must be physically liberated from each other. The degree of liberation will depend on the particle size in the grind. The report also gives washability data (fractional analyses following density separation) for Illinois No. 6, Pittsburgh, and Upper Freeport coals ground to -200 mesh. From the data it is estimated that an energy recovery of $80 \%$ requires mass recovery of around $70 \%$. The corresponding ash values based on the density separation are $3 \%$ to $4 \%$ while pyrite rejection is $85 \%$ to $95 \%$. These data should indicate the maximum potential for any cleaning method when these coals are ground to -200 mesh. Thus, the ash goal or $2 \%$ to $3 \%$ at $80 \%$ energy recovery is probably not achievable unless the coal is ground to a smaller size. The pyrite goal is achievable. This may be due to the higher density of pyrites than some other minerals, or to more efficient liberation of pyrites during grinding. 
Twenty-one beneficiation methods were compared in the report. Only three met the above critera. For these three, the coal had been ground to give volume mean diameters (VMD) of 13,7 and 4 microns. The best performance was at the smallest grind size. Two other techniques achieved the ash and pyrite removal specifications but not the minimum energy recovery. They had VMD's of 14 and 19 microns. The larger of these corresponds to the only dry electrostatic beneficiation method in the study. Energy recovery for that method was $72.4 \%$.

Methods of improving the efficiency of energy recovery by the electrostatic beneficiation technique are necessary. This may or may not involve finer grinding of the coal. Second pass separation of the refuse fraction or an alternate technique applied to the refuse fraction may yield the necessary energy recovery.

\section{Two-pass beneficiation}

One test was made in which each of the clean and refuse fractions of an electrostatic separation were passed again through the separator. The test was performed using -140 mesh $(105 \mu \mathrm{m})$ Illinois No. 6 coal. Powder was collected from each of the separator plates and passed back through the charger and separator. The results of measurements on the collected powder fractions are given in Table 1.

From the data, negatively charging particles tend to be smaller in size than positively charging particles. This probably indicates that mineral particles are usually smaller relative to the maceral particles.

We have not measured energy content for the different fractions. However, if we assume that energy content for a specific sample is approximately proportional to the non-ash fraction of the coal, then energy recovery can be estimated from the product of the mass fractions collected from the clean and refuse plates and their corresponding non-ash fraction. With this assumption a single pass through the separator resulted in $67.7 \%$ energy recovery in the clean fraction (negative plate). A second pass of the refuse (positive plate) portion through the separator gives an additional $19.2 \%$ energy recovery, however, the ash fraction for this portion is $5.3 \%$. Combining the two portions yields $86.9 \%$ energy recovery with an ash fraction of $3.5 \%$. This comes close to the desired requirements, although ash is slightly above the desired value. Measurements on pyritic sulfur have not been made. 
TABLE 1. Analysis of -140 mesh, Illinois No. 6 coal for two passes through a vertical electrostatic separator. The separator plates were $30 \mathrm{~cm}$ wide by $91 \mathrm{~cm}$ long and separated by $25 \mathrm{~cm}$ at the top and $10 \mathrm{~cm}$ at the bottom. A potential difference of $30 \mathrm{KV}$ was applied between the plates. The coal powder was triboelectrically charged against copper.

\begin{tabular}{|c|c|c|c|c|c|c|}
\hline $\begin{array}{l}\text { Coal } \\
\text { Source }\end{array}$ & $\begin{array}{c}\text { Tribo } \\
\text { Net } \mathrm{Q} / \mathrm{M} \\
(\mu \mathrm{C} / \mathrm{g})\end{array}$ & $\begin{array}{l}\text { Analysis } \\
\text { Fraction }\end{array}$ & $\begin{array}{l}\text { Mass } \\
\text { Fraction } \\
(\%)^{\mathrm{b}}\end{array}$ & $\begin{array}{l}\text { Total } \\
\text { Sulfur } \\
(\%)\end{array}$ & $\begin{array}{l}\text { Ash } \\
(\%)\end{array}$ & $\begin{array}{c}\text { Particle Diameter } \\
(\mu \mathrm{m}) \\
10 \%-50 \%-90 \%\end{array}$ \\
\hline I16-140 & & Feed & & 2.41 & $(7.9)^{d}$ & $5.7-33.0-100$ \\
\hline \multirow{3}{*}{$\begin{array}{l}\text { First Pass } \\
\text { through } \\
\text { separator }\end{array}$} & \multirow{3}{*}{-1.98} & Neg plate & 63 & 2.09 & 2.97 & $6.8-25.0-76.4$ \\
\hline & & Pos plate & 35 & $(2.92)^{d}$ & 16.56 & $1.65-12.8-63.1$ \\
\hline & & Filter & 1 & NA & NA & $12.5-63.7-141$ \\
\hline \multicolumn{7}{|c|}{ Second Pass } \\
\hline \multirow{2}{*}{$\begin{array}{l}\text { Neg plate } \\
\text { from first } \\
\text { pass }\end{array}$} & \multirow{2}{*}{+2.42} & Neg plate & $73 / 46$ & 1.93 & 1.93 & $7.3-28.4-69.5$ \\
\hline & & Pos plate & $25 / 15.8$ & 2.61 & 7.29 & $2.3-15.7-58.3$ \\
\hline \multirow{2}{*}{$\begin{array}{l}\text { Pos plate } \\
\text { from first } \\
\text { pass }\end{array}$} & \multirow{2}{*}{-3.70} & Neg plate & $53 / 18.6$ & 2.28 & 5.33 & $2.0-15.6-61.3$ \\
\hline & & Pos plate & $44 / 15.4$ & 3.67 & 30.58 & $1.8-11.1-52.6$ \\
\hline
\end{tabular}
a. Illinois No.6, -140 mesh.
b. Where two numbers are shown, the first represents the mass fraction for the run while the second represents the mass fraction relative to the mass of initial feed coal.
c. 50\% represents the volume median diameter (VMD). The first and last numbers in each series are the $10 \%$ and $90 \%$ cut points, respectively (i.e. $10 \%$ of the volume falls in sizes smaller than the first number). Measurements were made using a Microtrac particle analyzer.
d. Due to missing or questionable measurements, some numbers (indicated by parentheses) were calculated based on a 'mass balance' with the associated measurements.

Note also that significant additional reduction in both sulfur and ash are obtained by a second pass of the cleaned fraction though the separator. Ash is reduced from 2.97 to $1.93 \%$ and sulfur is reduced from 2.09 to $1.93 \%$, however, the energy content in the twice cleaned fraction is only about $45 \%$.

\section{Analysis of different sieve fractions}

Table 2 shows mass fraction, sulfur per cent, and particle diameters for the different collected fractions from the separator for different size frations of the feed coal. Note that a 
larger filter fraction is shown in this data than for the data in Table 1. This was in part due to a higher flow rate through the separator. The flow was quite turbulent in this set of runs which were performed earlier than those in Table 1.

TABLE 2. Analysis of Illinois No. 6 coal for different sieve fractions. The separator plates were $30 \mathrm{~cm}$ wide by $91 \mathrm{~cm}$ long and separated by $25 \mathrm{~cm}$ at the top and $10 \mathrm{~cm}$ at the bottom. A potential difference of $10 \mathrm{KV}$ was applied between the plates. The coal powder was triboelectrically charged against copper.

\begin{tabular}{|c|c|c|c|c|c|}
\hline $\begin{array}{l}\text { Coal } \\
\text { Source }\end{array}$ & $\begin{array}{c}\text { Tribo } \\
\text { Net } \mathrm{Q} / \mathrm{M} \\
(\mu \mathrm{C} / \mathrm{g})\end{array}$ & $\begin{array}{l}\text { Analysis } \\
\text { Fraction }\end{array}$ & $\begin{array}{l}\text { Mass } \\
\text { Fraction } \\
(\%)^{\mathrm{b}}\end{array}$ & $\begin{array}{c}\text { Total } \\
\text { Sulfur } \\
(\%)\end{array}$ & $\begin{array}{l}\text { Particle Diameter } \\
\qquad(\mu \mathrm{m}) \\
10 \%-50 \%-90 \%\end{array}$ \\
\hline \multirow{4}{*}{$\begin{array}{l}\text { Illinois } \\
\text { No. } 6 \\
-325 \\
\text { mesh }\end{array}$} & \multirow{4}{*}{-0.18} & Feed & 100 & $(3.03)$ & NA \\
\hline & & Neg plate & 37.9 & 2.54 & $7.6-19.1-41.9$ \\
\hline & & Pos plate & 25.4 & 3.54 & $7.2-18.4-53.8$ \\
\hline & & Filter & 15.7 & 3.19 & $1.4-8.3-28.4$ \\
\hline \multirow{4}{*}{$\begin{array}{l}\text { Illinois } \\
\text { No. } 6 \\
+325 \\
\text { mesh }\end{array}$} & \multirow{4}{*}{-0.013} & Feed & 100 & NA & NA \\
\hline & & Neg plate & 17.5 & NA & $12.1-44.4-100$ \\
\hline & & Pos plate & 11.5 & 3.36 & $3.5-38.7-99.5$ \\
\hline & & Filter & 71 & 2.61 & $98-243-447$ \\
\hline \multirow{4}{*}{$\begin{array}{l}\text { Illinois } \\
\text { No. } 6 \\
\text { Unsieved }\end{array}$} & \multirow{4}{*}{-.004} & Feed & 100 & $(2.56)$ & $\mathrm{NA}$ \\
\hline & & Neg plate & 33.7 & 2.29 & $3.0-21.9-93$ \\
\hline & & Pos plate & 25.5 & 3.32 & $1.6-13.9-84$ \\
\hline & & Filter & 40.8 & 2.85 & $115-245-449$ \\
\hline
\end{tabular}

a. 50\% represents the volume median diameter (VMD). The first and last numbers in each series are the $10 \%$ and $90 \%$ cut points, respectively (i.e. $10 \%$ of the volume falls in sizes smaller than the first number and $90 \%$ of the volume is in particle sizes smaller than the last number). Size measurements were made using a Microtrac FRA particle analyzer.

b. Due to missing or questionable measurements, some numbers (indicated by parentheses) were calculated based on a 'mass balance' with the associated measurements.

Of interest is the apparent variation in the sulfur content of the feed coal as a function of the sieve size. This needs to be confirmed with more data. For the -325 mesh, the particle size 
was smaller in the filter fraction than clean and refuse fractions. This differs from what we have seen with other feed sizes and with the previous separator configuration.

Our feed samples have been small and have been ground from one or a few chunks of coal just prior to separation. This has resulted in significant variation in the initial ash fraction resulting in variation in the ash fractions of the products. We need to correlate sulfur and ash in the products with the corresponding values for the feed coal where the quantities of sulfur and ash are covariates rather than control variables. Determination of the affects of other parameters such as grind size, moisture content, weathering, and charger operating conditions has been hampered by variations in the feed coal.

Possible ways around this problem are to grind large samples and use standard techniques to separate them into smaller representative samples which are then stored in inert atmospheres. Standard samples are available for some coals from DOE and these sources should be considered. We have avoided the use of preground samples due to the assumption that surface modifications occur over time after grinding even with good storage techniques. However, changes due to storage of ground coal in an inert atmosphere has not been demonstrated.

\section{Measurement of Charge to Mass Ratio as a Function of Height of Deposition}

We have developed a method to measure charge to mass ratio on particles deposited at different locations on the plate. A thin insulating tape placed onto the plates increases the decay time for charge on the deposited particles so that they can be collected from the plates into a Faraday cup. The Faraday cup consists of a conductive $25 \mathrm{~mm}$ filter holder inside an electric metal shield. Vacuum is connected to the bottom of the filter holder and a $1 / 4$ " flexible hose comes out of the top. The flexible hose can be placed against the separator plates to suck particles off at specific locations. The charge on the collected particles is measured with an electrometer and the entire filter holder is weighed to get the mass of the collected particles. 


\section{Charging of coal against different materials}

Charging the test surface by rubbing with a second material can simulate the conditions under which the material is likely to become charged in use. When two materials are rubbed together, the surfaces acquire a net electric charge, with one becoming negative and the other positive. For this experiment, two blocks of coal were selected. One is Illinois coal (from Illinois) and the other is Pittsburgh coal (from Pittsburgh). Seven materials were found to test the charging of the coal surface. They are: Nylon, Teflon, Steel, Brass, Copper, Aluminum and Wood. These materials were used to charge the fresh and oxidized coal surface separately. All measurements were carried out under normal laboratory condition, i.e., temperature in the range 16-20 $\mathrm{C}$ and humidity between 40 and $60 \%$. The coal surface was rubbed against a material for two minutes with some force by hands, and then the charge and charge decay on the coal surface were measured by an electrostatic voltmeter. The data was collected and stored by a computer. Fig. 1 and Fig. 2 are the results of the charging the coal surface (fresh and oxidized) by rubbing against different materials. We can see that most of the materials charged the fresh coal surface positive, except the Nylon material. This can be easily understood that Nylon is tender to transfer electrons to other materials, while Teflon is more inclined to receive electrons from other materials. We don't know the exact reason for Teflon. It should be positive as the fresh coal surface rubbing against Teflon. It is probably that the some small Teflon patches were transferred onto the coal surface. The inclination order of materials to receive the electrons from coal surface is Teflon, Steel, Brass, Wood, Aluminum, Copper, Nylon. As for the oxidized surface of coal, most of materials charged oxidized coal surface to negative (Fig. 2). This is because the coal surface intend to get electrons from other materials when it oxidized by oxygen in the air. The order of materials to receive the electrons from the coal surface is Wood, Aluminum, Teflon, Copper, Brass, Steel, Nylon. The work functions of several materials are listed in Table 3. 
Table 3. Work function of selected materials

\begin{tabular}{|c|c|c|}
\hline Materials & Work function (eV) & Source \\
\hline PTFE & 5.75 & Cross \\
\hline Nylon & $4.30-4.54$ & Cross \\
\hline $\mathrm{Cu}$ & $4.46-4.86$ & Charles \\
\hline $\mathrm{Fe}$ & 4.40 & Charles \\
\hline $\mathrm{Al}$ & $3.38-4.25$ & Charles \\
\hline
\end{tabular}

Cross, J. A., Electrostatics: principles, problems, and application, Adam Hilger, 1987, p29.

Charles, D., Hodgman, et al., Handbook of chemistry and physics 38 th ed, Chemical rubber publishing Co., Cleveland, Ohio.

The charge decay on the coal surface also was conducted with different materials. The electrostatic voltage on the coal surface was monitored by an electrostatic voltmeter. The electrostatic voltage on the coal surface will decreased gradually as the charge decaying on the coal surface. The data was transferred to a computer by an $A / D$ converter. The measured charge as a function of time can be written as

$$
q=q_{o} \exp (-t / \tau)
$$

where $q$ is the charge at time $t, q_{0}$ is the charge before the decay begins, $\tau$ is the time constant for charge decay. After substituting $\mathrm{q}=\mathrm{cv}$, where $\mathrm{c}$ is the capacity between the probe and the coal surface and $v$ is the potential that measured by the electrostatic voltmeter, the above equation also can be written as

$$
v=v_{0} \exp (-t / \tau)
$$

The fits for a single exponential decay model were not good representative to the experimental data. After discussing with Kelvin, we think the two decay mechanism might be suitable for our experiments (see the quarterly technical progress report, April 1996). 


$$
v=\left(v_{0}-v_{1}\right) \exp \left(-\frac{t}{\tau_{1}}-\frac{t}{\tau_{2}}\right)+v_{1} \exp \left(-\frac{t}{\tau_{2}}\right)
$$

where $v_{0}$ is the potential at $t=0, v_{1}$ is the potential below which the first decay mechanism is inactive, and $\tau_{1}$ and $\tau_{2}$ are the time constants for charge decay for the two decay mechanisms. And we assume that $\tau_{1}$, the time constant determining decay of surface charge, $\tau_{2}$, the rate constant for escape of deeply trapped charge carries. The above two decay model fits the experimental data quite well for the results (see enclosed example Fig. 1.3)

Unfortunately, achieving reproducible levels of charge by this method of triboelectrification is difficult. The charge is not guarantee uniformly over the rubbed surface and often patches of positive and negative charge are produced along side each other. And even more, when surfaces are rubbed and heat is generated that charging becomes much less predictable.

\section{Electrodynamic Balance}

Graduate student, Jian Zheng is preparing a dissertation proposal in which single coal particles will be examined in an electrodynamic balance. His report on the design of the balance is enclosed. 
$P 1=\left[\begin{array}{l}-11.748 \\ -5.238 \\ 43.041 \\ 431.086\end{array}\right] \quad P=\left(\begin{array}{c}-10.334 \\ 141.356\end{array}\right)$

Fig.1-3 Charge decay(old) (Pits-Nylon)

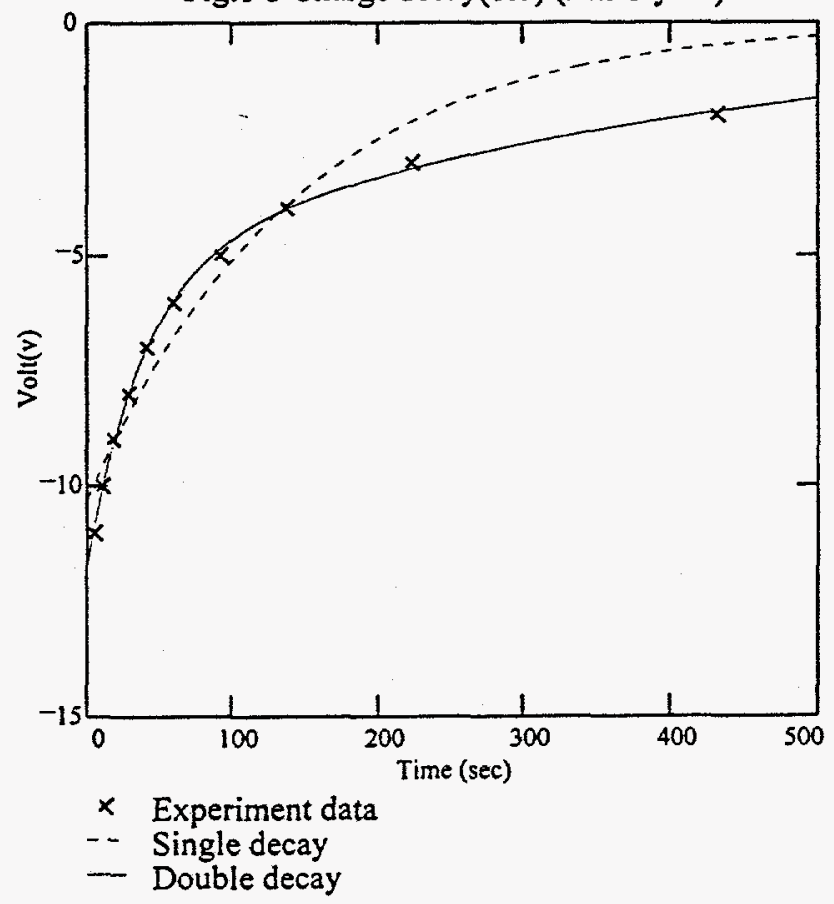




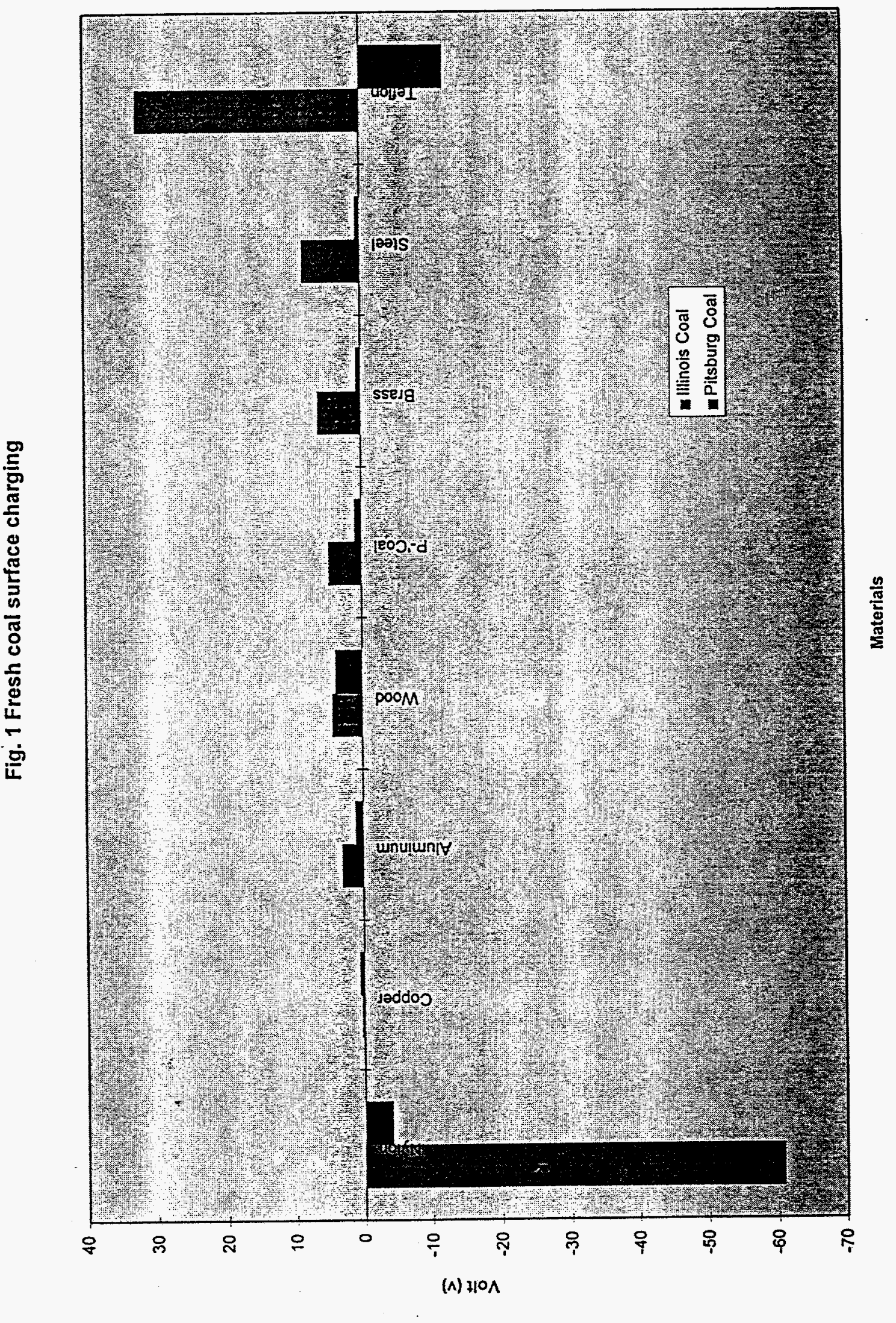




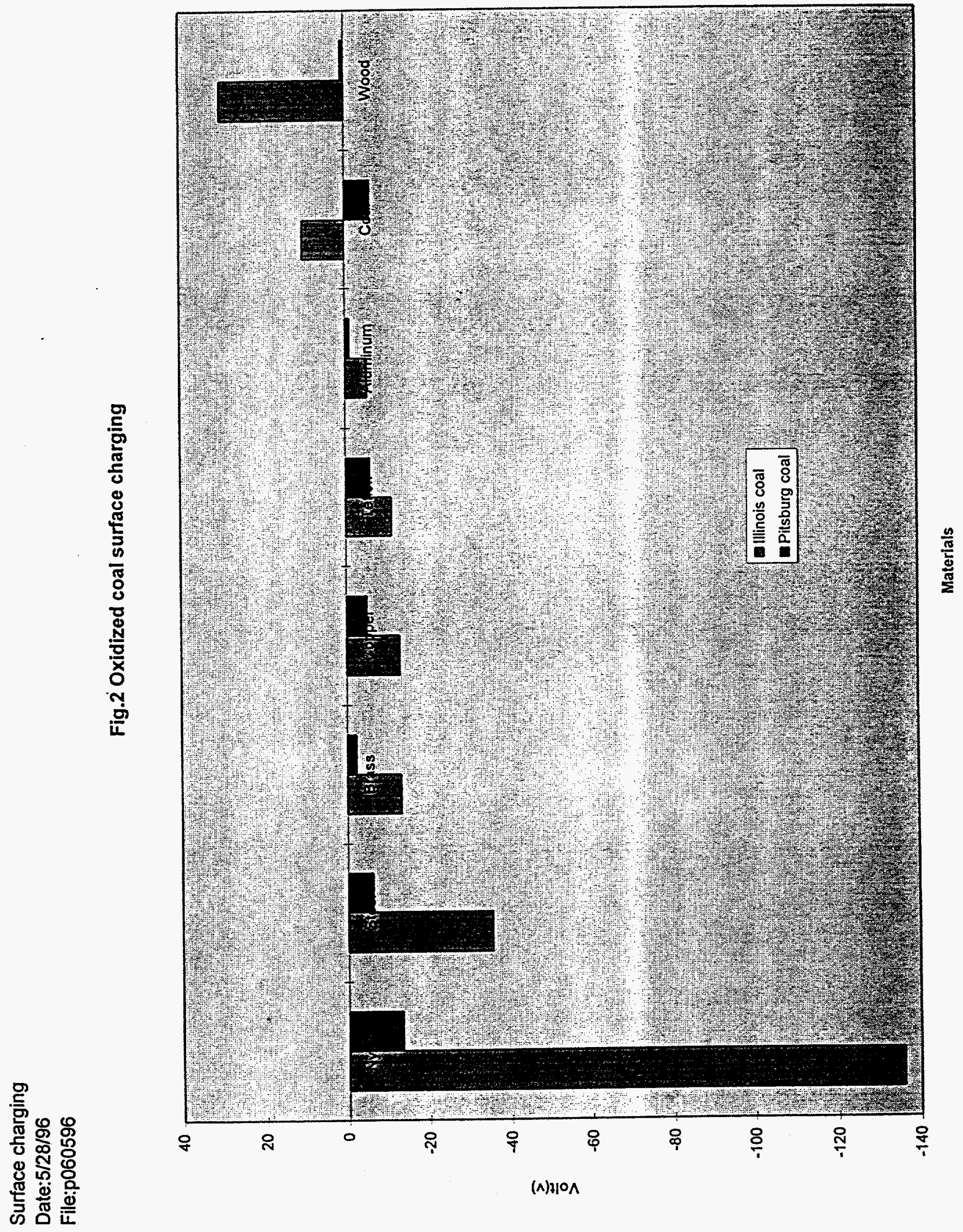




\section{DESIGN AND CONSTRUCT AN ELECTRODYNAMIC BALANCE Jian Zheng}

The electrodynamic balance will be designed and constructed as in Figure 3. The device will be used to freely levitate and hold a micron sized particle stationary in space for characterization. An electric field is used to balance the weight of the particle and to provide a focusing force to the particle if it deviates from the desired position. A few particles are injected and can be trapped in the balance by a particle generator. By manipulating the electric field strengths, a single particle can be chosen and held stationary for characterization while other extra particles are eliminated. The particle can then be studied as long as one wishes.

\section{BASIC PRINCIPLES OF ELECTRODYNAMIC TRAP}

The levitation of particles can be achieved by various methods: electrodynamic (Wuerker, Shelton and Langmuir, 1959), optical (Ashkin and Dziedzic, 1977), magnetic (Beams, 1950), and acoustic (Lee and Feng, 1982). Among them, the use of an electrodynamic balance is most popular in studying microparticle physics and chemistry. It has been used in numerous studies of the behavior of small particles and has proven to be particularly useful for the study of vapor pressures, solution thermodynamics, and optical properties of small particles. Bar Ziv and Sarofim (1991) have recently presented a comprehensive review of this instrument and its applications.

The elctrodynamic balance was originated from the Millikan oil droplet apparatus in which two large parallel plates were used to provide electrostatic trapping of a droplet. Apart from the edges, a uniform electric field exists and therefore a particle can be levitated anywhere between the plates. However, any convective current if it exists can carry the particle and no restoring force is available to maintain the particles at a predetermined position. Such restoring force can be supplied by insertion of an $\mathrm{AC}$ ring electrode between the $\mathrm{DC}$ plates.

The concept for the electrodynamic balance was described by Paul and Raether (1955) as an electric mass filter. In 1989, Paul and Dehmelt shared the Nobel Prize in Physics in their contributions on atomic spectroscopy of trapped ions. The electrodynamic balance is operated under the same principles although it traps a much greater mass particle. There are many possible geometries for the electrodynamic balance but the most common one was introduced by Wuerker et. al (1959) as the classical electrodynamic balance or quadrupole (Eversole and Lin, 1987). it consists of three electrodes; two end cap and a ring electrodes forming a bihyperboloidal surface as illustrated in Figure 1. DC is applied to the end caps to balance the weight of the particle and $\mathrm{AC}$ is applied to the ring electrode to provide focusing. A particle at the center of the ring feels no alternating potential, but as it deviates from the center, the particle is subjected to an alternating force. Averaged over the cycle and taking into account the phase lag caused by the inertia and the aerodynamic drag of the particle, this alternating force acts to restore the particle to the center.

If we apply a positive potential $+\mathrm{V}_{\mathrm{dc}}$ to the top electrode and negative potential $-\mathrm{V}_{\mathrm{dc}}$ to the bottom electrode, the uniform dc field $\mathrm{E}_{\mathrm{dc}}$ is given by 


$$
E_{d c}=-\frac{\left[+V_{d c}-\left(-V_{d c}\right)\right]}{2 z_{0}}=-\frac{V_{d c}}{z_{0}}
$$

Because this electrical field is uniform in the space between the electrodes, the particle can be suspended anywhere in that space provided that the electrostatic force $\left(F_{e}=q E_{d c}\right)$ on it balances the gravitational force, assuming that there are no other vertical forces on the object. A force balance yields

$$
-q \frac{V_{d c}}{z_{0}}=m g
$$

where $\mathrm{g}$ is the gravitational acceleration constant.

If we apply an ac potential $V_{a c}$ to the ring electrode, the dc field is not uniform, but the dc field at the center of the chamber $(r=0$ and $z=0)$ may be approximated by

$$
E_{d c}=-C_{0} \frac{v_{d c}}{z_{0}}
$$

Here $\mathrm{C}_{0}$ is a geometrical constant, the balance constant, which depends on the shapes of the electrodes and is affected by the existence of holes drilled through the electrodes for optical ports or for gas flow.

\section{LIMITATION OF TRAPPING}

The range of operation of the electrodynamic balance is remarkable, for masses ranging from about 10 ug $\left(10^{-5} \mathrm{~g}\right)$ to that of a single electron can be trapped. Many investigators have used the device to study aerosols since Davis and Ray (1980) introduced it to the aerosol community, for the instrument, coupled with light-scattering capabilities, is particularly well-adapted to the size range $0.05-50$ um.

However, the operating characteristics of the electrodynamic balance are governed by the equation of the particle motion, particularly the vertical component of the vectorial equation of the motion. The vertical forces can include aerodynamic drag, gravity, electrostatic and phonetic forces, and a force balance yields

$$
m \frac{d^{2} z}{d t^{2}}=-K_{d}\left(\frac{d z}{d t}-U_{g}\right)+F_{z}-m g+q E_{d c, z}+q E_{a c, z}
$$

where $\mathrm{z}$ is the vertical distance between the particle and the midplane of the balance, $\mathrm{U}_{\mathrm{g}}$ is the uniform gas velocity upstream of the particle, $F_{z}$ is any vertical force other than gravity, drag, and electrostatic, $E_{a c, z}$ and $E_{d c, z}$ are the vertical components of the ac and dc electrical field vectors, respectively, and $K_{s}$ is an aerodynamic drag parameter. For Stokes flow around a sphere in the continuum regime $K_{d}$ is given by 


$$
K_{d}=3 \pi d_{p} \eta
$$

where $d_{p}$ is the particle diameter and $\eta$ is the gas viscosity.

The first criterion for stable particle trapping is that the dc electrical field must be adjusted to balance all time-invariant vertical forces. Thus, one must adjust the dc potential to satisfy the force balance

$$
q E_{d c, z}=m g-K_{d} U_{g}-F_{z}
$$

If $E_{\mathrm{dc}, 2}$ is given by Eq. (3), Eq. (6) reduces to

$$
-C_{0} q \frac{V_{d c}}{z_{0}}=m g-K_{d} U_{g}-F_{z}
$$

In the absence of gas flow through the chamber and if there are no external forces other than gravity, Eq. (7) reduces to Eq. (2) in the case of $\mathrm{C}_{0}=1$.

Equation (7) is a necessary but not sufficient condition for stable levitation of a particle because the dynamics of the system are important. Using Eq. (6) in Eq. (4), the equation of the motion which governs the dynamics becomes

$$
m \frac{d^{2} z}{d t^{2}}=-K_{d} \frac{d z}{d t}+q E_{a c, z}
$$

In general, $\mathrm{E}_{\mathrm{ac}, \mathrm{z}}$ is a function of the radial and axial coordinates of the particle, and mathematical expressions for the component of the electrical field have been worked out for a few electrode configurations. In the absence of a dc bias voltage on the ring electrode of the bihyperboloidal configuration of Fig. 1, the radial and vertical components of the ac field are given by the following approximations valid to first-order in $\mathrm{r}$ and $\mathrm{z}$ :

$$
\begin{aligned}
& E_{a c, r}=-\frac{V_{a c}}{z_{0}^{2}} r \cos \omega t \text { and } \\
& E_{a c, z}=\frac{2 V_{a c}}{z_{0}^{2}} z \cos \omega t
\end{aligned}
$$

where $V_{a c, z} \cos \omega t$ is the ac potential applied to the ring electrode, $\omega=2 \pi f$, and $f$ is the frequency of the ac source. We have the following equation by substituting Eq. (9) into Eq. (8)

$$
m \frac{d^{2} z}{d t^{2}}+K_{d} \frac{d z}{d t}-\frac{q V_{a c}}{G} z \cos \omega t=0
$$


where $\mathrm{G}$ is a geometrical parameter which involves the size and shape of the ac electrode(s). For bihyperboloidal electrodes considered above, $\mathrm{G}=\mathrm{z}_{0}{ }^{2} / 2$.

This equation does not have stable solutions for all values of ac amplitude $V_{a c}$ and ac frequency $f$. the stability of the system is governed by an aerodynamic drag parameter $A=K_{d} / m \omega$ and an ac field strength parameter $B=2 \mathrm{qV}_{\mathrm{ac}} / \mathrm{m \omega}^{2} \mathrm{G}$. Figure 2 shows the stability regime. Note that if the field strength parameter $B$ is too large, a particle cannot be trapped. But B can be decreased either by decreasing $\mathrm{V}_{\mathrm{ac}}$ or by decreasing the ac frequency.

Reference:

Ashkin, A. and Dziedzic, J. M., Phys. Rev. Lett. 38, 1351 - 1354 (1977).

Bar, Ziv E. and Sarofim, A. F., Prog. Energy Combust: Sci. 17, 1 - 65 (1991).

Beams, J. W., Rev. Sci. Instr. 21, 182 - 184 (1950).

Davis, E. J., Ravindran, P., and Ray, A.K., Chem. Eng. Commun. 5, 251 (1980).

Eversole, J. D. and Lin, H. B., Rev. Sci. Instr. 58 (7), 1190 - 1194 (1987).

Lee, M. C., and Feng, I., Rev. Sci. Instr. 53, 854-859 (1982).

Paul, W. and Raether, M., Z. Phys. 140, 262 - 273 (1955). 


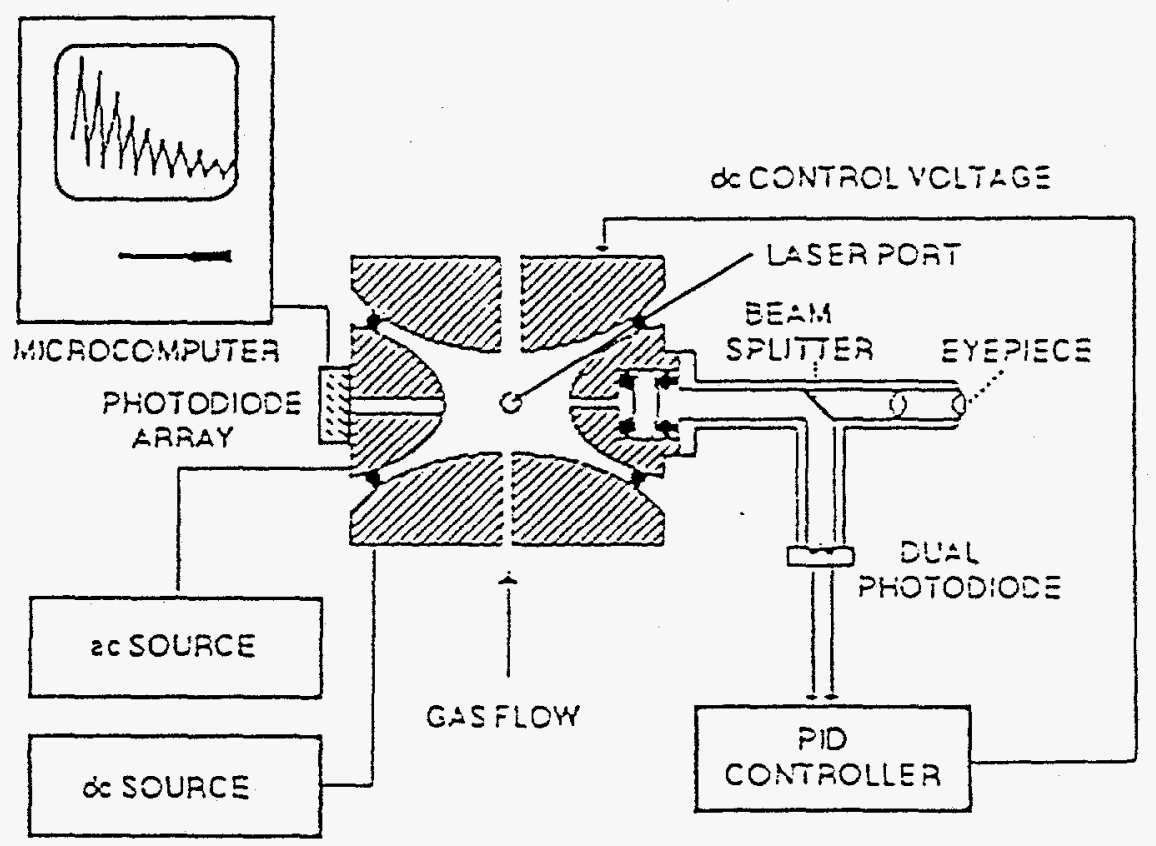

FIGLRE 1: The Bihyperboloidal Electrodynamic Balance Configuraijon with Eleciro-oplic Proportional,lniegraliDifierenial (PID) Feedback Conitol, (Source: Davis 1987.)

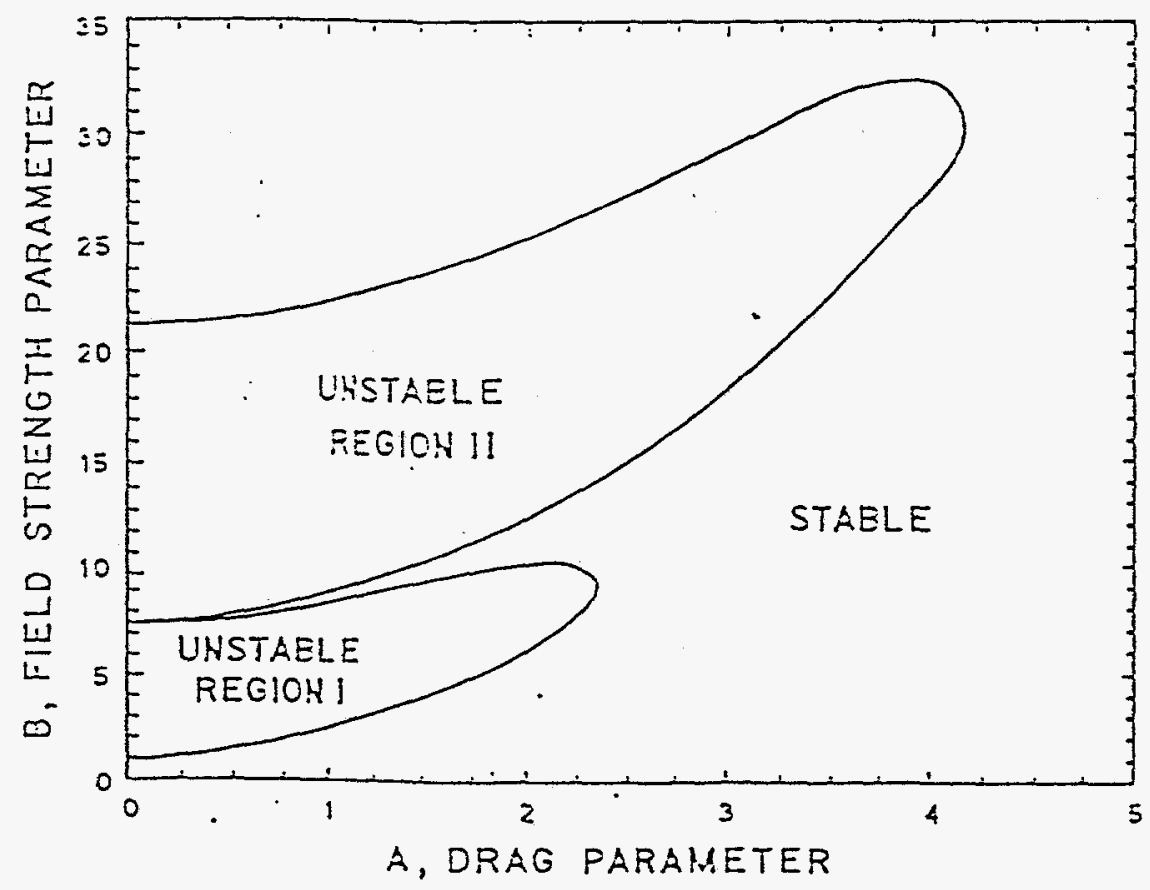

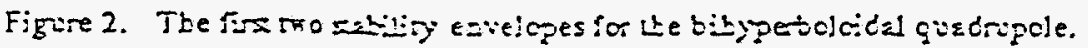

